Severe stress may precipitate transient, complex hallucinations, which the subject recognises as arising from his or her imagination. ${ }^{18} 19$ Dissociative (conversion) phenomena may account both for these pseudohallucinations and for many spiritual and paranormal phenomena.$^{820} \mathrm{~A}$ dissociative mechanism may also underlie memory flashbacks (which may be experienced as real $^{21}$ ) in post-traumatic stress disorder. ${ }^{22}$ Dissociative experiences may even be normal. ${ }^{8}$

Isolated hallucinations may be common and normal perceptual errors and no more indicative of psychiatric illness than isolated illusions. But, whether we describe visions and voices as psychotic, dissociative, hypnagogic, or normal, uncertainties remain about their underlying psychophysiology and the relations between these seemingly very different states of mind.

FRANCES KLEMPERER

Senior Registrar in General Psychiatry,

Bexley Hospital,

Bexley DA5 2BW
2 Posey TB, Losch ME. Auditory hallucinations of hearing voices in 375 normal subjects. Imagination, Cognition and Personality 1983-4;3:99-113.

Bentall RP, Slade P. Reliability of a scale measuring predisposition towards hallucination: a brief report. Fourmal of Personality and Individual Differences 1985;6:527-9.

Parkes CM. Bereavement and mental illness. Br F Med Psychol 1965;38:1-25.

Rees WD. The hallucinations of widowhood. BM7 1971;iv:37-41.

6 Sidgewick HA. Report of the census of hallucinations. Proceedings of the Society for Psychical Research, 1894:26:259-394.

West DJ. A mass

questionnaire on hallucinations. Fournal of the Society for Psychical Research, 1948:10:25-402.

8 Ross CA, Joshi S. Paranormal experiences in the general population. $f$ Nerv Ment Dis 1992;180:357-61.

9 James W. The varieties of religious experience. New York: Modern Library, 1902.

10 Holy Bible. Acts ix, 3-4.

11 Taymeeyah I. The jinn. Riyadh: Tawheed Publications, 1989. (Trans. Abu Ameenah Bilab Philips!

12 Slocombe J. Sailing alone around the world. London: Reprint Society, 1900.

13 Huxley A. Heaven and hell. New York: Perrenial Library, 1955.

14 Shaw G, Crossland J. Hallucinogenic drugs and altered states of consciousness. In: Underwood G, Stevens R, eds. Aspects of consciousness. Vol 2. London: Academic Press, 1981:185.

5 Waddington D. Socrates' symptom. Br f Psychiatry 1992;161:424-5.

16 Fenwick P, Galliano S, Coate MA, Rippere V, Brown D. Psychic sensitivity, mystical experience, head injury and brain pathology. Br $\mathcal{F}$ Med Psychol 1985:58:35-44.

Schacter DL. The hypnagogic state: a critical review of the literature. Psychol Bull 1976;83:452-81.

8 Goldstein AG. Hallucinatory experience: a personal account f A hnorm Psychol 1976:85:423-9.

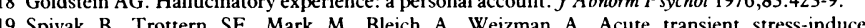

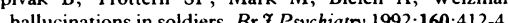

Wallace AFC. Stress and personality change. International Record of Medicine and General Practice Clinics 1956;169:12.

Clinics 1956;169:12.
Mueser KT, Butler RW. Auditory hallucinations in combat-related chronic posttraumatic stress Mueser KT, Butler RW. Auditory hallucinations
disorder. Am f Psychiatry 1987;144:299-302.

22 McGee R. Flashbacks and memory phenomena. F Nerv Ment Dis 1984;172:273-8.

\title{
Geoffrey Rose's big idea
}

\section{Changing the population distribution of a risk factor is better than targeting people at high risk}

We are all responsible for all. (Dostoevsky)

Few people have the greatness of heart and mind to be moved by mere statistics, and Geoffrey Rose, who recently retired from the chair of epidemiology at the London School of Hygiene and Tropical Medicine, is one of them. His valedictory book, The Strategy of Preventive Medicine, ${ }^{1}$ is written in an epidemiological tradition that goes back to the central ideas of the sanitary physicians of the previous century: the "patient" of preventive medicine is "the population," and its health is measured by statistics. Preventive measures aim to improve these statistics. The first quotation in the book comes from Virchow, reflecting on the link between the history of diseases and the history of human culture. The last sentence of the book echoes another Virchovian thought, that "medicine and politics cannot and should not be kept apart."

The book follows a crisp train of thought. It starts characteristically with Rose's rationale for prevention: "It is better to be healthy than ill or dead. That is the beginning and the end of the only real argument for preventive medicine. It is sufficient." Pivotal in Rose's argument is the "PlattPickering" controversy; he admits that "Pickering may have won the battle but lost the war." Sir George Pickering was the first to express the view that a sharp distinction between hypertension and normotension is a medical artefact. ${ }^{2} \mathrm{He}$ proposed that hypertension is a quantitative rather than a qualitative phenomenon. Rose maintains that Pickering failed to see the wider implications of his concept. Not only is it hard to tell where hypertension starts when you study the distribution of blood pressure within a population but it is equally hard to tell where dementia or osteoporosis begins when you study cognitive function or bone mineral density.

In addition, a risk factor usually gradually rather than abruptly increases the risk of disease. For example, the frequency of coronary heart disease rises gradually with blood pressure, with no sharp delineation of hypertensive and normotensive subjects. The presence of most people in the middle of the distribution of blood pressure implies that most patients with heart disease in whom raised blood pressure is a factor will have only moderately raised blood pressures. More clinical cases result from small but widespread risks than large but rare risks.

This leads to what Rose has coined the "prevention paradox": preventive actions that greatly benefit the population at large may bring only small benefits for individual people. This is the central issue in comparing the merits of the two main preventive strategies: the high risk approach and the population approach. The high risk approach aims to detect people at high risk of disease and lower their risk by treatment. The population strategy aims to shift the whole distribution of a risk factor in a favourable direction. Comparison of the two strategies suggests, in Rose's words, that "preventive medicine must embrace both, but, of the two, power resides with the population strategy." Thereby, Rose places himself squarely in a tradition that expects more from the population approach than from clinical medicine.

The implications are considerable. Much of the loss of life below the age of 65 results from potentially preventable diseases and events such as cardiovascular diseases, various types of cancer, accidents, and suicide. Rose does not treat these diseases systematically but discusses many quantitatively and qualitatively important conditions. There is some emphasis on coronary heart disease, the subject in which Rose first presented his views on the competing high risk and population strategies, but also on osteoporosis and fractures, Down's syndrome, and mental illnesses.

A problem is the general lack of data to support his view that preventive measures directed towards the whole population. will not only in theory but also in practice prevent disease. Rose is, of course, not to blame for this. On the contrary, he has been at the cradle of many studies that have accumulated knowledge about prevention. Still, his book is, perhaps necessarily so, largely based on circumstantial evidence.

The main question is whether a shift of the population distribution does indeed alter the risk. Part of the population may already be at so low a risk of a particular disease that manipulating the distribution of risk factors within the whole 
population will not benefit them. Envisaging how the effects of the population approach can be evaluated formally, in a way similar to evaluating the effects of the high risk approach, is also hard. The high risk approach lends itself easily to evaluation by randomised controlled trials; the effect of the intervention on the risk factor, whether blood pressure, cognitive function, or bone mineral density, is soon obvious in people with extreme values, and the ultimate clinical benefits of the intervention, if they exist, are soon apparent. Deciding whether lowering the risk of a whole population provides the expected benefits, however, is not really amenable to classical randomised trials. It would require a change in lifestyle for many, starting from birth, and the benefits would be reaped only decades later. Definitive proof might always remain elusive. This is a plea not for complacency or fatalism but for a creative use of data from observational studies. The generation after Pickering and Rose has its work cut out.

Rose has carefully collected evidence to support his major theme. Still, the case for the population approach is not made naively as was sometimes done by the sanitary physicians in the past century and by early chronic disease epidemiologists in this one. People, and even their governments, retain the right to be foolish - the choice is theirs. Experts are gravely cautioned not to confound scientific results with personal prejudice. Also, the clinical or high risk approach is not despised as Rose is firmly convinced that you should not criticise a measure for what it fails to do but appreciate it for what it can do.

The Strategy of Preventive Medicine is the legacy of a life spent in the pursuit of better health for populations. The book exemplifies the humility of its acknowledgement, which, in effect, states that the thoughts of one person are only the modifications of the thoughts of a great many others. Rose does not shrink from controversy or self scrutiny. The book deserves to be read by all who care either for individual people or for populations. They will be confronted by some extremely clear thinking on crucially important topics.

A HOFMAN

Professor of Epidemiology

Erasmus University,

Rotterdam,

The Netherlands

J P VANDENBROUCKE

Leiden University,

Leiden,

The Netherlands

1 Rose G. The strategy of preventive medicine. Oxford: Oxford University Press, 1992 2 Swales JD, ed. Platt versus Pickering. An episode in recent medical history. London: Keynes Press,

\section{The ups and down of bungee jumping}

\section{Check the rope; forget the intravenous line}

In bungee jumping one end of an elastic rope is attached to the feet of someone prepared to jump from a great height - for example, a platform, bridge, or crane. The other end is made firm at the jumping off point. When the rope reaches its elastic limit the downward plunge is translated into an upward motion, returning the jumper almost, but not quite, to the jumping off point. The jumper oscillates to and fro until finally coming to rest. The sport is not new. Over 20 years ago David Attenborough recorded the initiation rites of some Pacific islanders, which required initiates to leap well over $30 \mathrm{~m}$ from a bamboo platform. To their legs was attached not a bungee rope but a length of vine. Each man was accompanied by a seconder, who encouraged his charge to jump by flaying his torso with a venomous plant.

Bungee jumping's increasing popularity raises two questions: why do people do it, and is it safe? Presumably people do it because it is very exciting - a "charge" lasting several days has been claimed to follow a single jump. Attempts have been made to see whether any hormonal changes might explain this elevation of mood.

In one study an experienced bungee jumper made several descents while hooked up to an intravenous line. Concentrations of $\beta$ endorphin, growth hormone, prolactin, testosterone, and follicle stimulating hormone did not change. ${ }^{1}$ But the results might have been different had the subject been an innocent bystander, pounced on and hurled from the jumping platform without warning. ${ }^{2}$

Feelings of exhilaration and wellbeing, often lasting several hours, are common after the stress of intense exercise. Few hormonal changes, however, are consistently found in athletes-whether recreational or Olympic class-after exercise. They are limited to a rise in plasma cortisol concentration and a small fall in testosterone concentration. ${ }^{3+}$ There must surely be some changes in neurotransmitter concentrations in the brain, but these are unlikely to be detectable in peripheral blood.

Undoubtedly, bungee jumping can be dangerous, although whether the sport should be blamed for the death of a fairground worker who forgot to attach his rope to anything is doubtful. ${ }^{5}$ Lethal accidents, however, have occurred after miscalculations of the extent to which the rope will stretch.

But the dangers of other sports should not be forgottenmountaineering and motor racing come immediately to mind. For these sports, however, the risks are tempered by a measure of skill. With bungee jumping there are no skills, and unless the total number of jumps made is known, estimation of the risks of a single jump is not possible. Apart from death nothing more serious than periorbital bruising has been reported.

So far, those taking part have usually been young, willing, and able, but now that bungee jumps are being performed for charity other people, who may not be so well prepared, will inevitably be drawn in. The crop of injuries resulting from stunts performed for charity such as parachute jumping should make us cautious. Who will decide whether a person is fit to participate and on what grounds? And who will bear the responsibility when things go wrong?

\section{MARK HARRIES}

Consultant Physician,

Northwick Park Hospital,

Harrow HAl 3UJ

1 Zimmerman U, Loew T, Wildt L. "Stress hormones" and bungee-jumping. Lancet 1992;340 428.

Vandenbroucke JP. Bungee-jumping and design of experiments. Lancet 1992;340:800.

Wheeler GD, Wall SR, Belcastro AN, Cumming DC. Reduced serum testosterone and prolectin levels in male distance runners. FAMA 1984;252:514-6.

4 Bullen BA, Skrinar GS, Beintins IZ, Cass DB, Reppert SM, Dotson CO, et al. Endurance training effects on plasma hormone responsiveness and sex hormone excretion. $\mathcal{F}$ Appl Physio 1984;56:1453-63.

5 Loose end kills bungee jumper. Today 1992; Aug 3. 